\title{
Structural Identification of Modified Amino Acids on the Interface between EPO and Its Receptor from EPO BRP, Human Recombinant Erythropoietin by LC/MS Analysis
}

\author{
Kwang-Eun Song ${ }^{2,3}$, Jaehee Byeon ${ }^{2}$, Dae-Bong Moon ${ }^{3}$, Hyong-Ha Kim ${ }^{4}$, Yoo-Joo Choi ${ }^{1}$, and \\ Jung-Keun Suh ${ }^{1, *}$
}

\begin{abstract}
Protein modifications of recombinant pharmaceuticals have been observed both in vitro and in vivo. These modifications may result in lower efficacy, as well as bioavailability changes and antigenicity among the protein pharmaceuticals. Therefore, the contents of modification should be monitored for the quality and efficacy of protein pharmaceuticals. The interface of EPO and its receptor was visualized, and potential amino acids interacting on the interface were also listed. Two different types of modifications on the interface were identified in the preparation of rHu-EPO BRP. A UPLC/Q-TOF MS method was used to evaluate the modification at those variants. The modification of the oxidized variant was localized on the Met54 and the deamidated variants were localized on the Asn47 and Asn147. The extent of oxidation at Met54 was $3.0 \%$ and those of deamidation at Asn47 and Asn147 were 2.9\% and $4.8 \%$, respectively.
\end{abstract}

\section{INTRODUCTION}

Recombinant human erythropoietin (rHu-EPO) is a 30,400 Dalton, 165-amino-acid glycosylated protein having more than $40 \%$ carbohydrate contents by mass (Davis et al., 1987). rHuEPO has been used for the treatment of the anemia associated with chronic renal failure over a decade (Eschbach et al., 1989; Winearls et al., 1986). The mode of action for the treatment with $\mathrm{rHu}$-EPO is well-understood. The binding of EPO to specific receptors on cell surface triggers intracellular signaling path-

\footnotetext{
${ }^{1}$ Department of Newmedia, Korean German Institute of Technology, ${ }^{2}$ Department of Stereoscopic Media, Korean German Institute of Technology, ${ }^{3}$ BIOnSYSTEMS, Inc., R\&D Center, ${ }^{4}$ Center for Bioanalysis, Korea Research Institute of Standards and Science, Korea

*Correspondence: jksuh@kgit.ac.kr
}

Received 28 July, 2014; revised 1 September, 2014; accepted 4 September, 2014; published online 30 Spetember, 2014

Keywords: deamidation, erythropoietin, interface, modification, oxidation ways and results in the proliferation and differentiation of cells, and finally to an increase in haematocrit (Lodish et al., 1995).

The interaction between EPO and its receptor is wellcharacterized by structural determinations using nuclear magnetic resonance (NMR) spectroscopy (Cheetham et al., 1998) and X-ray crystallography (Syed et al., 1998). These studies have proposed the potential amino acids involved in the interactions between EPO and its receptor. There are two binding sites for those interactions. Residues involved in the binding site 1 of EPO are Thr44 and Asn147 hydrogen bonded to the Phe93 of the receptor, and Arg10 and Arg14 of EPO interacting with Met150 of the receptor (Syed et al., 1998).

Any chemical or post-translational modification on amino acids of EPO in the binding sites invariably affects interactions between the EPO and its receptor and may result in lower EPO therapeutic efficacy. In the case of EPO, glycosylation has been well-documented as a post-translational modification. The $\mathrm{N}$ glycosylations are important factors for the stability, pharmacokinetics, and biological activity of EPO (Delorme et al., 1992; Toyoda et al., 2000). However, other modifications have not been well-investigated because of the complex isoform profiles of EPO due to glycosylation.

Biopharmaceuticals are highly complex protein molecules and may have some types of modification during upstream and downstream processes. These changes may influence the safety, purity, potency, and strength of products, which must be well-characterized, controlled, and monitored as part of the manufacturing process (Greer et al., 2002; Walsh, 2010). In the case of EPO, the quality of four different products has been investigated and compared using several bioanalytical techniques (Brinks et al., 2011). All products showed differences in terms of content and potency with the differences in isoform profiles resulting from distinct glycosylation (Brinks et al., 2011). It's been suggested that monitoring of product quality is needed using physicochemical and biological analysis (Brinks et al., 2011).

For the focused characterization of modifications in EPO, we investigated modifications on the binding sites between EPO and its receptor which may affect the efficacy of EPO. To get detailed information on the interface of EPO and its receptor, 
Variant Identification on the Interface of EPO and Receptor

Kwang-Eun Song et al.

Table 1. Potential amino acids identified on the interface interacting between EPO and its receptors

\begin{tabular}{|c|c|c|c|c|c|}
\hline \multirow{2}{*}{ Binding site } & \multicolumn{2}{|c|}{ EPO receptor } & \multicolumn{2}{|c|}{ EPO } & \multirow{2}{*}{ Potential modification } \\
\hline & Position & Amino acid & Position & Amino acid & \\
\hline \multirow[t]{12}{*}{ Site 1} & 93 & PHE & 44 & THR & \\
\hline & 92 & SER & 45 & LYS & Acetylation \\
\hline & 93 & PHE & 46 & VAL & \\
\hline & 91 & SER & 47 & ASN & Deamidation \\
\hline & 93 & $\mathrm{PHE}$ & 48 & PHE & \\
\hline & 33 & LEU & 48 & PHE & \\
\hline & 34 & GLU & 49 & TYR & Sulfation \\
\hline & 34 & GLU & 52 & LYS & Acetylation \\
\hline & 93 & PHE & 147 & ASN & Deamidation \\
\hline & 204 & SER & 150 & ARG & \\
\hline & 93 & PHE & 151 & GLY & \\
\hline & 93 & $\mathrm{PHE}$ & 155 & LEU & \\
\hline \multirow[t]{7}{*}{ Site 2} & 150 & MET & 10 & ARG & \\
\hline & 150 & MET & 11 & VAL & \\
\hline & 150 & MET & 14 & ARG & \\
\hline & 93 & PHE & 15 & TYR & Sulfation \\
\hline & 91 & SER & 100 & SER & Phosphorylation \\
\hline & 62 & GLU & 103 & ARG & \\
\hline & 92 & SER & 104 & SER & Phosphorylation \\
\hline
\end{tabular}

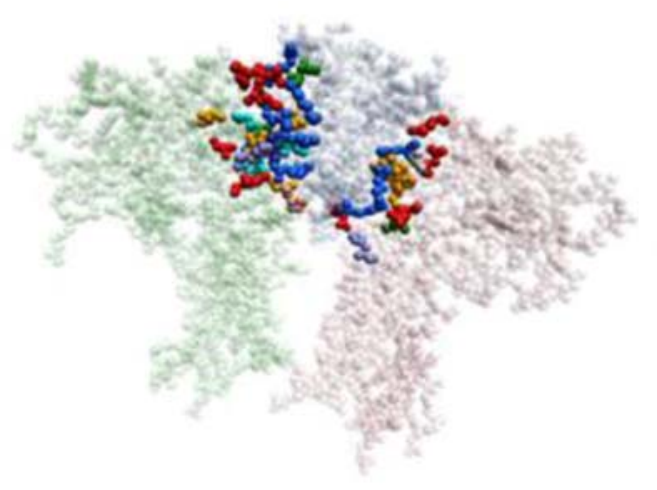

we first identified and visualized amino acids involved in the interaction between EPO and its receptor. Afterwards, a UPLC/Q-TOF method was used to evaluate the modifications on the amino acids. This study led to the identification of several modifications on the interface of EPO and its receptor including Asn47, Met54, and Asn147 localized on the binding site 1.

\section{MATERIALS AND METHODS}

Materials

EPO BRP (EDQM, Ph. Eur.) contains a freeze-dried preparation of erythropoietin in vials with a declared content of $250 \mu \mathrm{g}$ of erythropoietin per vial. This erythropoietin BRP is known as a 50:50 mixture of epoetin alfa (The R.W. Johnson pharmaceutical Research Institute) and epoetin beta (Boehringer-Mannheim, recently Roche).

Endoproteinase trypsin was purchased from Roche. Sodium

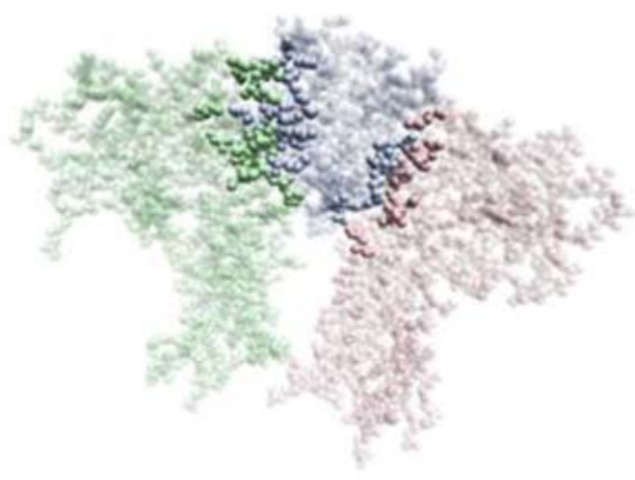
phosphate, monobasic and dibasic, DTT, and guanidine- $\mathrm{HCl}$ were purchased from Sigma. Acetonitrile (ACN), TFA and methanol were purchased from $B \& J$. Acetic acid was purchased from J.T. Baker.

Visualization of the interface of EPO and its receptor To get detailed information on the interface of EPO and its receptor, a visualization tool was developed using ESBTL and OpenGL libraries. Residue information including geometry, chains, and amino acids were extracted from a PDB file loaded with the tool of ESBTL libraries. The distance between amino acids on the interface from different chains was calculated based on the $x, y$, and $z$ coordinates from the geometry information extracted. The

Fig. 1. Visualization of the interfaces interacting between EPO and its receptors. PDB ID, 1EER (6) was used for the analysis and potential amino acids on the interfaces were shown high-lighted with different colors representing different amino acids. potential amino acids interacting on the interface were visualized based on the cut-off values of the calculated distance information using OpenGL libraries. 1EER PDB file (6) was used to visualize the interface of EPO and its receptor. 
Table 2. Tryptic peptide identified for rHu-EPO

\begin{tabular}{|c|c|c|c|c|c|c|c|c|}
\hline Peptide & $\begin{array}{l}\text { Peptide } \\
\text { number }\end{array}$ & Start & End & $\begin{array}{l}\text { Expected } \\
\text { mass (Da) }\end{array}$ & $\mathrm{RT}(\mathrm{MIN})$ & $\begin{array}{c}\text { Determined } \\
\text { mass (Da) }\end{array}$ & $\begin{array}{l}\text { Intensity } \\
\text { (counts) }\end{array}$ & $\begin{array}{l}\text { Mass error } \\
(\mathrm{ppm})\end{array}$ \\
\hline APPR & $\mathrm{T} 1$ & 1 & 4 & 439.254 & 2.4 & 439.248 & 13823 & -13.4 \\
\hline LICDSR & $\mathrm{T} 2$ & 5 & 10 & 705.348 & 18.0 & 705.345 & 31894 & -4.0 \\
\hline VLER & T3 & 11 & 14 & 515.307 & 5.2 & 515.302 & 41869 & -8.5 \\
\hline YLLEAK & $\mathrm{T} 4$ & 15 & 20 & 735.417 & 29.1 & 735.412 & 78761 & -6.0 \\
\hline $\begin{array}{l}\text { EAENITTGCAEHC } \\
\text { SLNENITVPDTK }\end{array}$ & T5* & 21 & 45 & 8700.025 & 41.2 & 8700.047 & 2397 & 2.5 \\
\hline VNFYAWK & T6 & 46 & 52 & 926.465 & 45.5 & 926.461 & 50313 & -4.3 \\
\hline $\mathrm{R}$ & $\mathrm{T7}$ & 53 & 53 & 174.112 & & & & \\
\hline $\begin{array}{l}\text { MEVGQQAVEVW } \\
\text { QGLALLSEAVLR }\end{array}$ & T8 & 54 & 76 & 2525.331 & 82.8 & 2525.337 & 519433 & 2.5 \\
\hline $\begin{array}{l}\text { GQALLVNSSQPW } \\
\text { EPLQLHVDK }\end{array}$ & T9* & 77 & 97 & 5365.126 & 52.4 & 5365.163 & 51575 & 6.9 \\
\hline AVSGLR & T10 & 98 & 103 & 601.355 & 9.9 & 601.350 & 45475 & -7.2 \\
\hline SLTTLLR & T11 & 104 & 110 & 802.491 & 41.3 & 802.489 & 103380 & -3.5 \\
\hline ALGAQK & T12 & 111 & 116 & 586.344 & 3.6 & 586.339 & 43321 & -9.2 \\
\hline EAISPPDAASAA PLR & $\mathrm{T} 13$ & 117 & 131 & 2411.970 & 36.2 & 2412.008 & 205918 & 15.6 \\
\hline EAISPPDAASAA PLR & $\mathrm{T} 13^{\star *}$ & 117 & 131 & 1464.757 & 36.2 & 1464.759 & 14912 & 1.2 \\
\hline TITADTFR & $\mathrm{T} 14$ & 132 & 139 & 923.471 & 32.7 & 923.467 & 64969 & -5.2 \\
\hline $\mathrm{K}$ & $\mathrm{T} 15$ & 140 & 140 & 146.106 & & & & \\
\hline KLFR & T15-16 & 140 & 143 & 562.359 & 14.0 & 562.356 & 3445 & -4.8 \\
\hline LFR & $\mathrm{T} 16$ & 141 & 143 & 434.264 & 10.4 & 434.260 & 5578 & -8.5 \\
\hline VYSNFLR & $\mathrm{T} 17$ & 144 & 150 & 897.471 & 38.2 & 897.468 & 44547 & -3.1 \\
\hline GK & $\mathrm{T} 18$ & 151 & 152 & 203.127 & & & & \\
\hline LK & T19 & 153 & 154 & 259.190 & & & & \\
\hline LKLYTGEACR & T19-20 & 153 & 162 & 1152.596 & 36.3 & 1152.586 & 1671 & -9.1 \\
\hline LYTGEACR & $\mathrm{T} 20$ & 155 & 162 & 911.417 & 25.7 & 911.413 & 46068 & -4.1 \\
\hline TGD & $\mathrm{T} 21$ & 163 & 165 & 291.107 & & & & \\
\hline
\end{tabular}

*, N-glycopeptide; **, O-glycopeptide

Peptide mapping with trypsin

The protein sample $(100 \mu \mathrm{g})$ was reduced and denatured with 1 $\mathrm{M}$ DTT and $6 \mathrm{M}$ guanidine- $\mathrm{HCl}$ respectively. The denaturation of protein sample was digested with trypsin on a ratio of 1 to 20 (trypsin to protein ratio) for $4 \mathrm{~h}$ at $37^{\circ} \mathrm{C}$. The obtained peptides were separated using reversed phase chromatography with ACQUITY UPLC system (Waters, UK) equipped with ACQUITY BEH300 C18 column $(1.7 \mu \mathrm{m} 2.1 \times 150 \mathrm{~mm}) .10 \mu \mathrm{l}$ of peptide solutions were injected on the column with $0.2 \mathrm{ml} / \mathrm{min}$ flow rate at the temperature of $50^{\circ} \mathrm{C}$. Mobile phase A was $0.1 \%$ TFA in water and $B$ was $0.1 \%$ TFA in ACN with a gradient of $0-50 \%$ B in 90 min. The tryptic map was generated by monitoring the absorbance of the effluent with a UV detector at $215 \mathrm{~nm}$. The assignment of each peptide was based on the analysis by an online electrospray ionization mass spectrometry (Q-TOF). MS spectra were obtained with the entire $0.2 \mathrm{ml} / \mathrm{min}$ column effluent over a range of $50-3,000$ in mass-tocharge ratio with the setting of collision energy at $6 \mathrm{~V}$ and cone voltage at $35 \mathrm{~V}$. Calibration of the mass spectrometers with NaCsI was performed and [Glu1]-fibrinopeptide B was used in the lockspray channel. The tryptic peptides were identified using BioPharmaLynx Software (Waters, UK) and the sequences of peptides were determined using PLGS Software (Waters, UK).

\section{RESULTS}

Identification of potential amino acids interacting on the interface of EPO and its receptor

The detailed structural information on the interfaces of EPO and its receptor was visualized using ESBTL and OpenGL libraries. Two binding sites between EPO and its receptor were clearly identified and visualized (Fig. 1). The potential amino acids interacting on the interface were also identified and highlighted in Fig. 1. Amino acid residues localized on $A B$ coil and helix $D$ of EPO were identified on the binding site 1 and residues found on helices $A$ and $C$ of EPO were identified on the binding site 2 (Table 1 ). Some amino acid residues on the binding site 1 were involved in forming the hydrophobic cap of EPO which was in contact to Phe93 for its receptor by hydrophobic interactions. Two amino acid residues of EPO, Thr44, and Asn147 were known to be hydrogen-bonded with Phe93 of its receptor. Most residues of EPO on the binding site 2 were hydrophilic and forming a hydrophilic pocket flanked by three Arg residues. Potential modifications specific to the amino acid residues are listed on Table 1. Four types of common modification are possible for the residues on the interfaces, including acetylation, deamidation, sulfation, and phosphorylation. 
Variant Identification on the Interface of EPO and Receptor

Kwang-Eun Song et al.

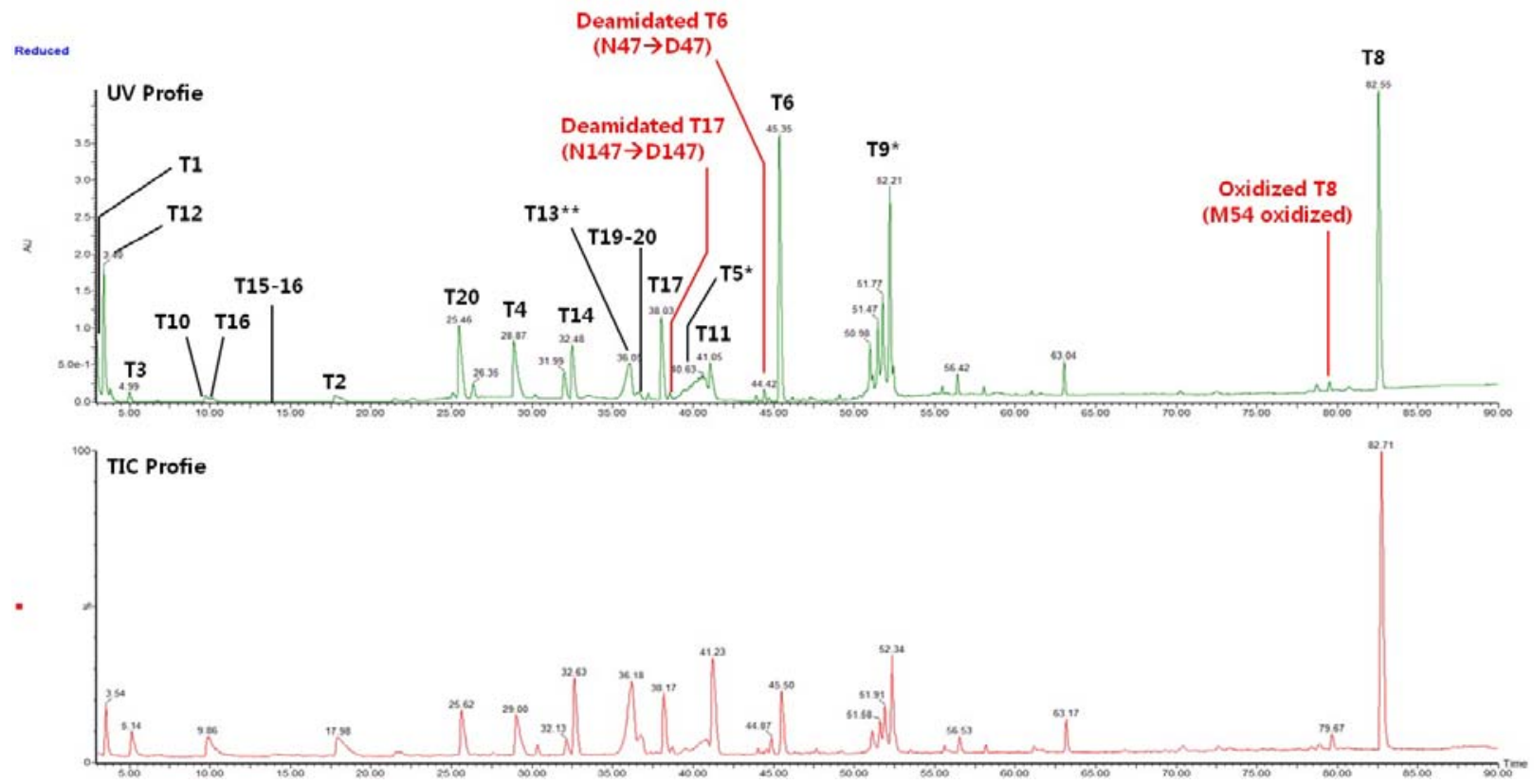

Fig. 2. Tryptic map of rHu-EPO under reduced condition. *, N-glycopeptide; **, O-glycopeptide.

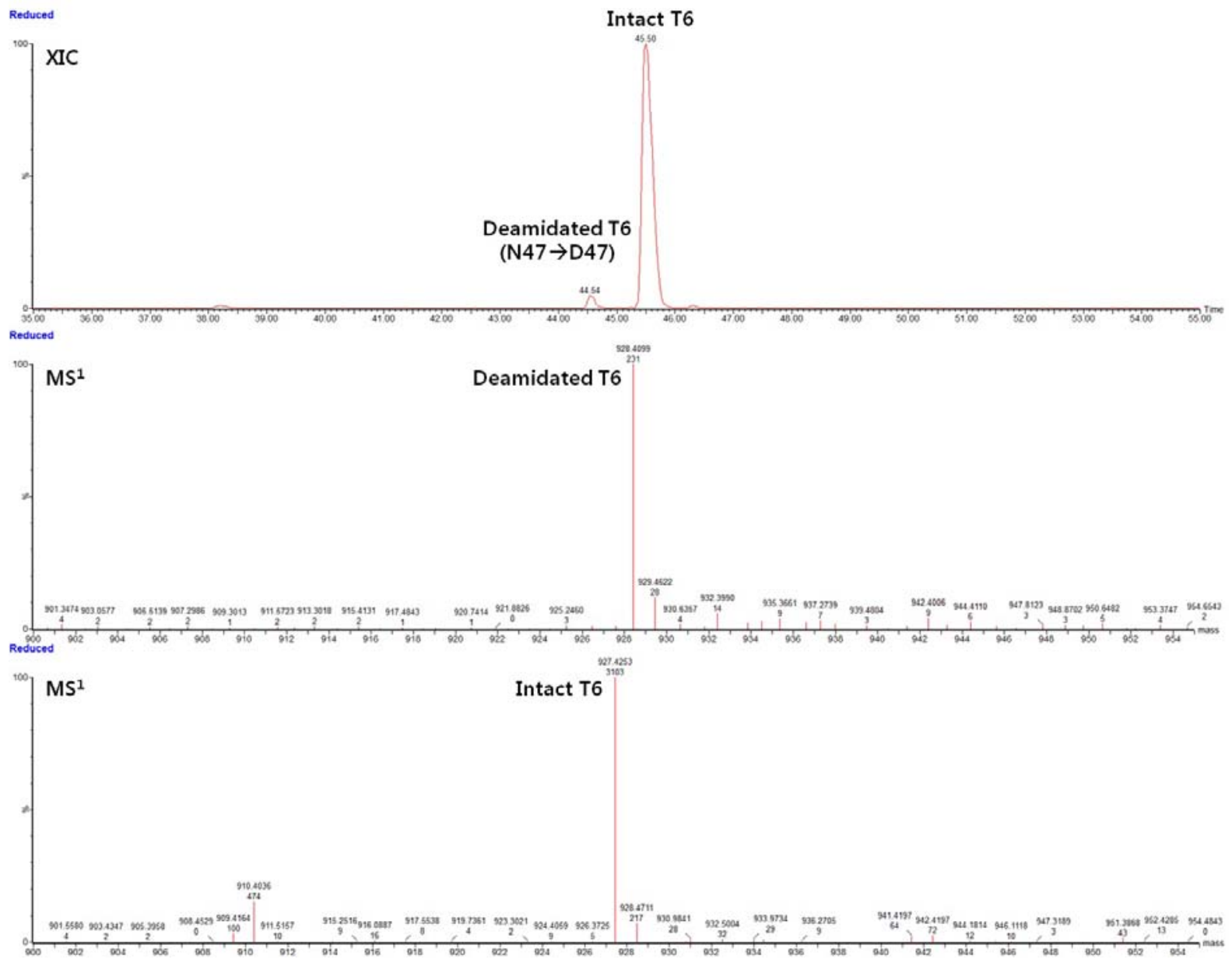

Fig. 3. Identification of deamidation on Asn47 from T6 peptide 
Table 3. Identification of deamidation at Asn47 of T6 peptide

\begin{tabular}{ccccccccccc}
\hline Peptide & $\begin{array}{c}\text { Peptide } \\
\text { number }\end{array}$ & Start & End & Modifiers & $\begin{array}{c}\text { Expected } \\
\text { mMass } \\
(\mathrm{Da})\end{array}$ & RT (MIN) & $\begin{array}{c}\text { Deter- } \\
\text { mined } \\
\text { mass } \\
\text { (Da) }\end{array}$ & $\begin{array}{c}\text { Intensity } \\
\text { (counts) }\end{array}$ & $\begin{array}{c}\text { Mass } \\
\text { error } \\
\text { (ppm) }\end{array}$ & $\begin{array}{c}\% \\
\text { Total }\end{array}$ \\
\hline VNFYAWK & T6 & 46 & 52 & & 926.465 & 45.5 & 926.468 & 50313 & -4.3 & 97.1 \\
VNFYAWK & T6* & 46 & 52 & $\begin{array}{c}\text { Deamidatio } \\
\mathrm{n} \mathrm{N}(1)\end{array}$ & 927.449 & 44.6 & 927.4479 & 1523 & -1.2 & 2.9 \\
\hline
\end{tabular}

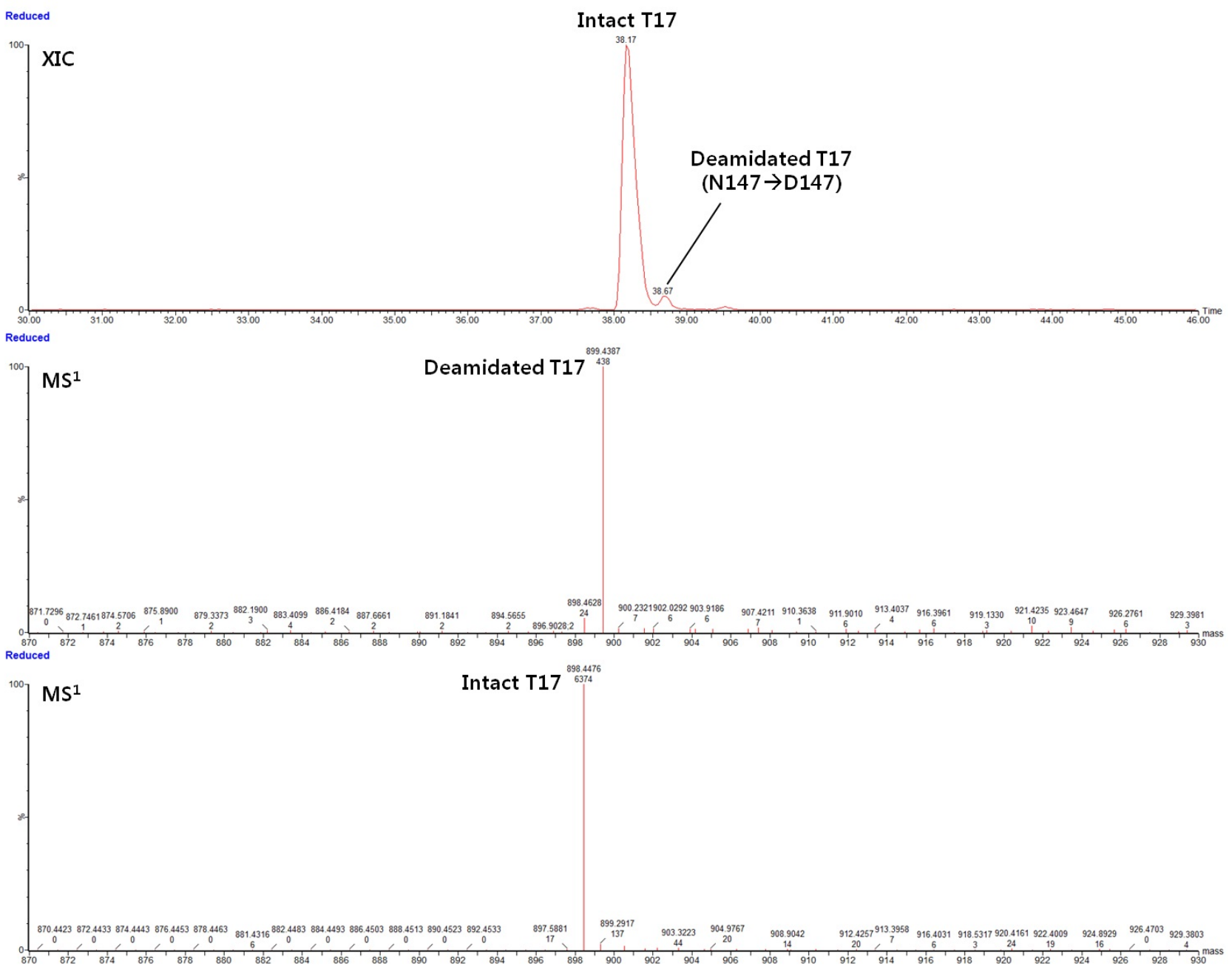

Fig. 4. Identification of deamidation on Asn417 from T17 peptide

Peptide mapping analysis of EPO

In order to get detailed information on any potential modifications, peptide mapping analysis was carried out using endoprotease trypsin and subsequent separation of peptide fragments by RP-UPLC. The tryptic peptides were identified by UV monitoring and online mass spectrometry. The tryptic map was generated based on the assignment of each peptide identified.

EPO consists of 165 amino acids, and 21 peptides are expected with the digestion of trypsin. T5 peptide with
Asn24/Asn38 and T9 peptide with Asn83 are expected on the glycopeptides with N-glycans. T13 peptide with Ser126 is also expected on the glycopeptides with O-glycans.

A tryptic map of rHu-EPO under reduced condition is shown in Fig. 2 along with TIC profile. The map covers the full sequences of EPO, with the exception of the small polar peptides, T7 $\left({ }^{53} R^{53}\right)$, T18 $\left({ }^{151} G^{152}\right)$, and T21 $\left({ }^{163} \mathrm{TGD}^{165}\right)$. Therefore, the LC-MS of tryptic fragments confirmed $96.4 \%$ coverage of the primary sequence for $\mathrm{rHu}$-EPO. Most amino acid residues on the 
Variant Identification on the Interface of EPO and Receptor

Kwang-Eun Song et al.

Table 4. Identification of deamidation at Asn147 of T17 peptide

\begin{tabular}{|c|c|c|c|c|c|c|c|c|c|c|}
\hline Peptide & $\begin{array}{c}\text { Peptid } \\
\text { number }\end{array}$ & Start & End & Modifiers & $\begin{array}{r}\text { Expected } \\
\text { mass }(D a)\end{array}$ & RT (MIN) & $\begin{array}{c}\text { Deter- } \\
\text { mined } \\
\text { mass (Da) }\end{array}$ & $\begin{array}{l}\text { Intensity } \\
\text { (counts) }\end{array}$ & $\begin{array}{l}\text { Mass } \\
\text { error } \\
(\mathrm{ppm})\end{array}$ & \% Total \\
\hline VYSNFLR & 1:T017 & 144 & 150 & & 897.4708 & 38.2 & 897.468 & 44547 & -3.1 & 95.2 \\
\hline VYSNFLR & 1:T017* & 144 & 150 & $\begin{array}{c}\text { Deamidatio } \\
n N(1)\end{array}$ & 898.4548 & 38.8 & 898.4493 & 2257 & -6.1 & 4.8 \\
\hline
\end{tabular}

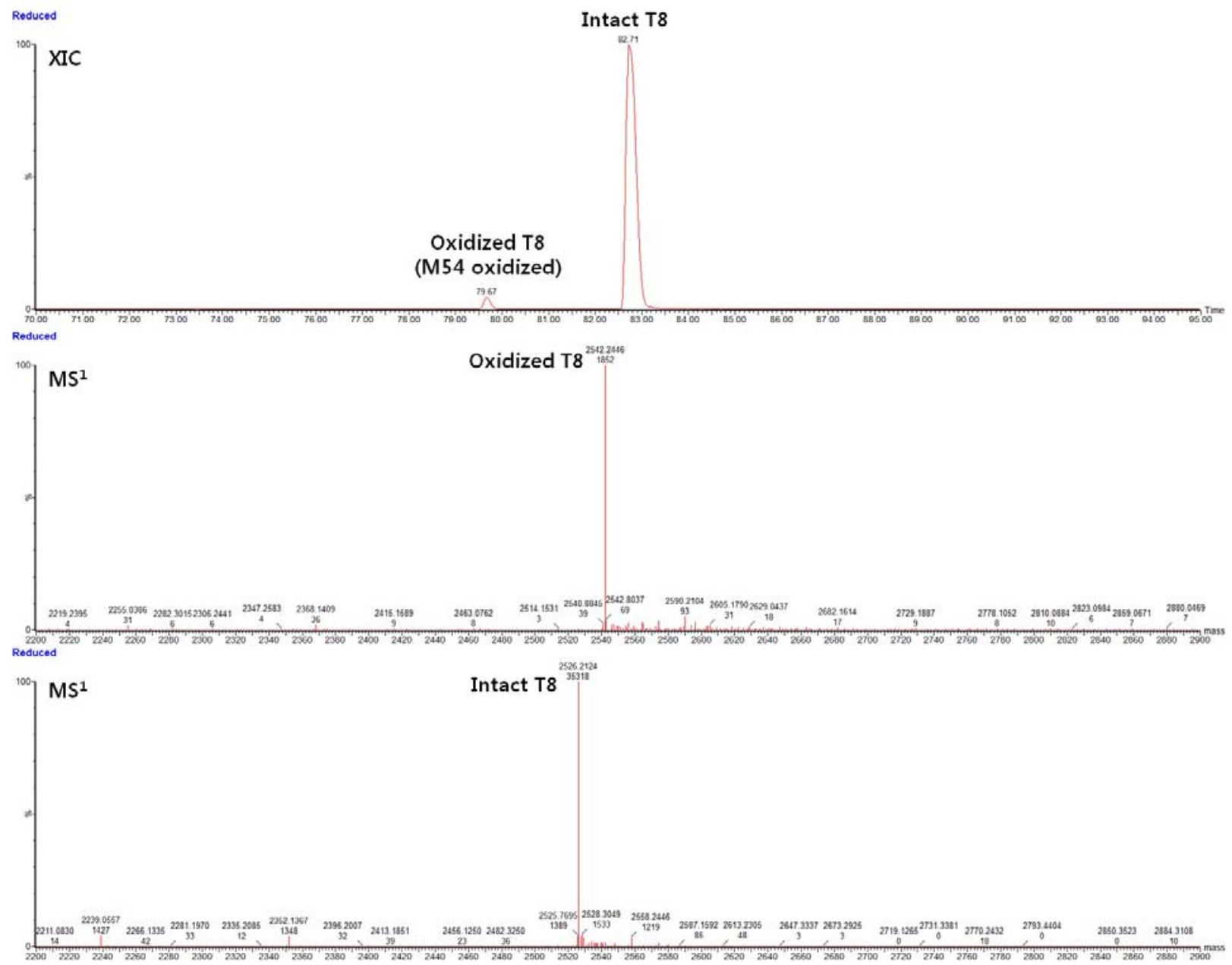

Fig. 5. Identification of oxidation on Met54 from T8 peptide

binding site 1 and 2 were localized on the tryptic map besides Gly151 which was not identified. T6 and T17 peptides having most of the residues from the binding site 1 were identified at the retention time of $45.4 \mathrm{~min}$ and $38.0 \mathrm{~min}$ on the UV profile of the tryptic map respectively. T3 and T10 peptides having most of residues from the binding site 2 were identified at the retention time of $5.0 \mathrm{~min}$ and $9.7 \mathrm{~min}$ on the UV profile of the tryptic map respectively (Table 2 ).

Identification of modified amino acids on the interface interacting between EPO and its receptor

The measured masses of the found tryptic peptides were com- pared to the theoretical masses calculated from the amino acid sequences and the differences were monitored to verify the modifications of amino acid residues on the binding sites. Two deamidated peptides originated from T6 and T17 were detected on the tryptic map during these processes. The deamidated amino acids were further localized on Asn47 and Asn147 which were located on the binding site 1.

The masses of modified T6 peptide were measured and compard to the theoretical masses calculated from the amino acid sequence. T6 peptide had the sequences of ${ }^{46} \mathrm{VNFYAWK}^{52}$ having one potential deamidation site at Asn47. The expected molecular mass of T6 peptide was $926.47 \mathrm{Da}$ and intact T6 
Table 5. Identification of oxidation at Met54 of T8 peptide

\begin{tabular}{|c|c|c|c|c|c|c|c|c|c|c|}
\hline Peptide & $\begin{array}{l}\text { Peptide } \\
\text { number }\end{array}$ & Start & End & Modifiers & $\begin{array}{l}\text { Expected } \\
\text { mass }(\mathrm{Da})\end{array}$ & RT (MIN) & $\begin{array}{c}\text { Deter- } \\
\text { mined } \\
\text { mass }(\mathrm{Da})\end{array}$ & $\begin{array}{l}\text { Intensity } \\
\text { (counts) }\end{array}$ & $\begin{array}{l}\text { Mass } \\
\text { error } \\
(\mathrm{ppm})\end{array}$ & $\begin{array}{c}\% \\
\text { Total }\end{array}$ \\
\hline $\begin{array}{l}\text { MEVGQQ } \\
\text { AVEVWQ } \\
\text { GLALLSE } \\
\text { A VLR }\end{array}$ & 1:T008 & 54 & 76 & & 2525.3311 & 82.8 & 2525.3334 & 519433 & 2.5 & 97 \\
\hline $\begin{array}{l}\text { MEVGQQ } \\
\text { AVEVWQ } \\
\text { GLALLSE } \\
\text { A VLR }\end{array}$ & 1:T008* & 54 & 76 & $\begin{array}{l}\text { Oxidation } \\
\qquad M(1)\end{array}$ & 2541.3259 & 79.7 & 2541.3423 & 15922 & 6.5 & 3 \\
\hline
\end{tabular}

peptide having the expected mass was identified at $45.5 \mathrm{~min}$ on the TIC profile of the tryptic map (Fig. 3 and Table 3). Deamidated T6 peptide having 927.45 Da which was about $0.98 \mathrm{Da}$ larger than intact T6 peptide was identified at $44.6 \mathrm{~min}$ on the TIC profile of the tryptic map. The relative content of deamidated T6 peptide was 2.9\% of total (Fig. 3 and Table 3).

The masses of modified T17 peptide were measured and compared to the theoretical masses calculated from the amino acid sequence. T17 peptide had the sequences of ${ }^{144}$ VYSNFLR $^{150}$ having one potential deamidation site at Asn147. The expected molecular mass of T17 peptide is 897.47 $\mathrm{Da}$ and intact T17 peptide having the expected mass was identified at 38.2 min on the TIC profile of the tryptic map (Fig. 4 and Table 4). Deamidated T17 peptide having 898.45 Da which was 0.98 Da larger than intact T17 peptide was identified at $38.8 \mathrm{~min}$ on the TIC profile of the tryptic map and the relative content of deamidated T17 peptide was $4.8 \%$ of the total (Fig. 4 and Table 4).

Along with deamidation at Asn47 and Asn147, one oxidized peptide originating from T8 was also detected. The oxidized amino acids were further localized on Met54 which was located on the hydrophobic cap of the EPO.

The masses of modified T8 peptide were measured and compared to the theoretical masses calculated from the amino acid sequence. T8 peptide had the sequences of ${ }^{54}$ MEVGQQAVEVWQGLALLSEAVLR ${ }^{76}$ having one potential oxidation site at Met54. The expected molecular mass of T8 peptide is $2525.33 \mathrm{Da}$ and intact T8 peptide having the expected mass was identified at $82.8 \mathrm{~min}$ on the TIC profile of the tryptic map (Fig. 5 and Table 5). Oxidized T8 peptide having 2541.33 Da which was about 16.00 Da larger than intact T8 peptide was identified at $79.7 \mathrm{~min}$ on the TIC profile of the tryptic map. The relative content of oxidized T8 peptide was $3.0 \%$ of the total (Fig. 5 and Table 5).

\section{DISCUSSION}

Potential amino acid residues were visualized and identified at the interfaces of EPO and its receptor. These were localized on AB coil (residues 44 to 52) and helix D (Asn147, Arg150, Gly151, and Leu155) on the binding site 1 and found on helices A (Arg10, Val11, Arg14, and Tyr15) and C (Ser100, Arg103, and Ser104) on the binding site 2. Mutations on amino acid residues within these two binding sites of EPO prevented interac tion to it's the receptor and finally abolished erythropoietic activities of EPO (Brines et al., 2008; Elliott et al., 1997; Gan et al.,
2012). Thus, any chemical modifications on these residues which were generated during the manufacturing process of rHu-EPO may also affect the efficacy of the final product so the quality issues those modifications should be identified, wellcharacterized, and monitored.

In order to take a close look at potential modifications at the interfaces, we've first done peptide mapping analysis of rHuEPO with trypsin and checked if tryptic peptides containing amino acids on the interfaces would be identified. What we found was that most amino acid residues except Gly151 on the binding sites 1 and 2 were localized on the identified tryptic peptides.

Deamidations which converted Asn to Asp were identified at two amino acid residues, Asn47 and Asn147, on the binding site 1 . The relative contents of deamidated residues were in the range of $3-5 \%$ of the total, which are larger than $1 \%$ of total purity and may require detailed characterization for regulation and authorization.

Asn147 of EPO is known to be involved in hydrogen bonding to the Phe93 of its receptor (Syed et al., 1998). Mutational analysis showed that the mutant rHu-EPO on Asn147 to Lys (rHuEPO[N147K]) reduced affinity for a receptor binding over 100fold and in vitro activity over 200-fold (Elliott et al., 1997). Deamidation on Asn147 seems to be similar effects as the mutant, rHu-EPO(N147K). Deamidation on Asn newly generated negatively charged Asp on that position. This modification may change hydrogen bonding capacity between Asn147 of EPO and Phe83 of its receptor and subsequently affect not only receptor binding activity but also in vitro biological activity.

Based on structural data (PDB ID code, 1EER), Asn47 of EPO seemed to be involved in hydrogen bonding to Ser91 of its receptor while the adjacent Lys45 also had the same orientation to Ser91 as Asn47. Mutational data on Asn47 was not available but the mutant rHu-EPO on Lys45 to Asp [rHuEPO(K45D)] which had the same orientation to Ser91 of its receptor showed 500-fold reduced affinity for receptor binding and 5000 -fold reduced in vitro activity. The new negatively charged Asp47 by deamidation may produce effects similarly as the mutant, rHu-EPO(K45D).

Along with deamidation, another modification, oxidation, was identified at an amino acid residue, Met54. This modification was identified when rHu-EPO was under stress at pH 9 (Chang et al., 2013). Met54 was placed in the hydrophobic cap of EPO. Along with Met54, several amino acid residues on the binding site 1 were involved in forming the hydrophobic cap of EPO, which consisted of Val46, Phe48, Trp51, Met54, and Leu155 of 
EPO. This hydrophobic cap was in contact to the Phe93 of its receptor by hydrophobic interactions. Under the stress, the compact structure of the hydrophobic cap was loosened and Met54 may be vulnerable to be oxidized. Thus, Met54 can be used for a structural indicator of EPO. The content of oxidation on Met54 can be quantified and used for monitoring the structural characteristics of EPO.

The binding of the ligand protein to the specific receptor is major mode of action for most biopharmaceutical therapies. Our studies provide a targeted method focusing on the interface between the ligand and its receptor, which is coupled with UPLC-MS application. This method may contribute a novel and valuable tool which can be used to identify modification hotspots of protein pharmaceuticals.

\section{ACKNOWLEDGMENTS}

The authors thank scientists at BIOnSYSTEMS, Inc. (Seoul, Korea) for assistance with UPLC / Q-TOF MS.

\section{REFERENCES}

Brines, M., Patel, N.S., Villa, P., Brines, C., Mennini, T., De Paola, M., Erbayraktar, Z., Erbayraktar, S., Sepodes, B., Thiemermann, C., et al. (2008). Nonerythropoietic, tissue-protective peptides derived from the tertiary structure of erythropoietin. Proc. Natl. Acad. Sci. USA 105, 10925-10930.

Brinks, V., Hawe, A., Basmeleh, A.H., Joachin-Rodriguez, L., Haseberg, R., Somsen, G.W., Jiskoot, W., and Schellekens, H. (2011). Quality of original and biosimilar epoetin products. Pharm. Res. 28, 386-393.

Chang, S.H., Kim, H.J., and Kim, C.W. (2013). Analysis of the structure and stability of erythropoietin by $\mathrm{pH}$ and temperature changes using various LC/MS. Bull. Korean Chem. Soc. 34, 2663-2670.

Cheetham, J.C., Smith, D.M., Aoki, K.H., Stevenson, J.L., Hoeffel, T.J., Syed, R.S., Egrie, J., and Harvey, T.S. (1998). NMR structure of human erythropoietin and a comparison with its receptor bound conformation. Nat. Struct. Biol. 5, 861-866.
Davis, J.M. Arakawa, T, Strickland, TW., and Yphanitis, D.A (1987). Characterization of recombinant human erythropoietin produced in Chinese hamster ovary cells. Biochemistry 26, 2633-2638.

Delorme, E., Lorenzini, T., Giffin, J., Martin, F., Jacobsen, F., Boone, T., and Elliott, S. (1992). Role of glycosylation on the secretion and biological activity of erythropoietin. Biochemistry 31, 98719876.

Elliott, S., Lorenzini, T., Chang, D., Barzilay, J., and Delorme, E. (1997). Mapping of the active site of recombinant human erythropoietin. Blood 89, 493-502.

Eschbach, J.W., Abdulhadi, M.H., Browne, J.K., Delano, B.G. Downing, M.R., Egrie, J.C., Evans, R.W., Friedman, E.A., Graber, S.E., Haley, N.R., et al. (1989). Recombinant human erythropoietin in anemic patients with end-stage renal disease. Results of a phase III multicenter clinical trial. Ann. Intern. Med. 111, 992-1000.

Gan, Y., Xing, J., Jing, Z., Stetler, R.A., Zhang, F., Luo, Y., Ji, X., Gao, Y., and Cao, G. (2012). Mutant erythropoietin without erythropoietic activity is neuroprotective against ischemic brain injury. Stroke 43, 3071-3077.

Greer, F., Reason, A., and Rogers, M. (2002). Post-translational modifications of biopharmaceuticals-a challenge for analytical characterisation. Eur. Biopharm. Rev. 106-111.

Lodish, H.F., Hilton, D.J., Klingmuller, U., Watowich, S.S., and Wu, H. (1995). The erythropoietin receptor: biogenesis, dimerization, and intracellular signal transduction. Cold Spring Harb. Symp. Quant. Biol. 60, 93-104.

Syed, R.S., Reid, S.W., Li, C., Cheetham, J.C., Aoki, K.H., Liu, B. Zhan, H., Osslund, T.D., Chirino, A.J., Zhang, J., et al. (1998) Efficiency of signaling through cytokine receptors depends critically on receptor orientation. Nature 395, 511-516.

Toyoda, T., Itai, T., Arakawa, T., Aoki, K.H., and Yamaguchi, H. (2000). Stabilization of human recombinant erythropoietin through interactions with the highly branched $\mathrm{N}$-glycans. J. Biochem. 128, 731-737.

Walsh, G. (2010). Post-translational modifications of protein biopharmaceuticals. Drug Discov. Today 15, 773-780.

Winearls, C.G., Oliver, D.O., Pippard, M.J., Reid, C., Downing, M.R. and Cotes, P.M. (1986). Effect of human etythropoietin derived from recombinant DNA on the anaemia of patients maintained by chronic haemodialysis. Lancet 328, 1175-1178. 